\title{
The Emerging Role of Exercise Testing and Stress Echocardiography in Valvular Heart Disease
}

\author{
Eugenio Picano, MD, PHD, ${ }^{*}$ Philippe Pibarot, MD, PHD, † Patrizio Lancellotti, MD, PHD, \\ Jean Luc Monin, MD, PHD,§ Robert O. Bonow, MD\| \\ Pisa, Italy; Québec City, Québec, Canada; Liège, Belgium; Créteil, France; and Chicago, Illinois
}

\begin{abstract}
Exercise testing has an established role in the evaluation of patients with valvular heart disease and can aid clinical decision making. Because symptoms may develop slowly and indolently in chronic valve diseases and are often not recognized by patients and their physicians, the symptomatic, blood pressure, and electrocardiographic responses to exercise can help identify patients who would benefit from early valve repair or replacement. In addition, stress echocardiography has emerged as an important component of stress testing in patients with valvular heart disease, with relevant established and potential applications. Stress echocardiography has the advantages of its wide availability, low cost, and versatility for the assessment of disease severity. The versatile applications of stress echocardiography can be tailored to the individual patient with aortic or mitral valve disease, both before and after valve replacement or repair. Hence, exercise-induced changes in valve hemodynamics, ventricular function, and pulmonary artery pressure, together with exercise capacity and symptomatic responses to exercise, provide the clinician with diagnostic and prognostic information that can contribute to subsequent clinical decisions. Nevertheless, there is a lack of convincing evidence that the results of stress echocardiography lead to clinical decisions that result in better outcomes, and therefore large-scale prospective randomized studies focusing on patient outcomes are needed in the future. (J Am Coll Cardiol 2009;54:2251-60) (C) 2009 by the American College of Cardiology Foundation
\end{abstract}

Advances in diagnosis and risk stratification, combined with steady progress in surgical valve replacement and repair, have led to improved outcomes of patients with valvular heart disease over the past 5 decades. The most important indication for surgical intervention in patients with hemodynamically significant aortic or mitral valve disease is the development of symptoms, as emphasized in recent guidelines $(1,2)$. Because symptoms may develop slowly and indolently in these chronic conditions, many patients are unaware of subtle changes in effort tolerance, even when questioned directly by their physicians. Hence, guidelines of both the American College of Cardiology/American Heart Association (ACC/AHA) and the European Society of Cardiology (ESC) $(1,2)$ have placed renewed emphasis on the role of exercise testing to provide objective evidence of exercise capacity and symptom status. In addition, although Doppler echocardiography at rest is the method of choice

From the ${ }^{*} \mathrm{CNR}$, Institute of Clinical Physiology, Fondazione G. Monasterio, Pisa, Italy; †Quebec Heart and Lung Institute, Laval University, Québec City, Québec, Canada; $¥$ Department of Cardiology, University Hospital of Sart Tilman, Liège, Belgium; §Department of Cardiology, Assistance Publique-Hôpitaux de Paris, Henri Mondor Hospital, Créteil, France; and the $\|$ Division of Cardiology, Northwestern University Feinberg School of Medicine, Chicago, Illinois. Dr. Pibarot has a long-term loan of a Doppler echocardiographic system by GE Healthcare.

Manuscript received February 5, 2008; revised manuscript received July 8, 2009, accepted July 28, 2009. for assessing severity of valvular disease, there is a growing use of stress 2-dimensional and Doppler echocardiography to assess dynamic changes in hemodynamics in concert with the clinical findings of exercise testing.

Stress echocardiography is well established for evaluating patients with coronary artery disease (CAD) (3-5). The role of stress echocardiography for the assessment of the hemodynamic consequences of valvular lesions was initially proposed in the 1980s $(6,7)$ but only recently gained recognition by specialized and general guidelines $(1,2,8,9)$. In a number of patients with valvular heart disease, particularly those with low-flow, low-gradient aortic valve stenosis (AS), stress echocardiography provides additional information regarding severity of disease and hence aids in risk stratification and clinical decision making.

The majority of the recommendations in the guidelines do not have an extensive evidence base, underscoring the need for more clinical investigation in this area. In valvular heart disease, exercise testing is preferred over pharmacological stress because it provides insights regarding exertional symptoms and blood pressure responses. The exception is the use of pharmacologic stress echocardiography in patients with low-flow, low-gradient AS. Supine bicycle exercise is recommended because Doppler information can be obtained during the different stages of exercise $(8,9)$, rather than post-treadmill imaging, when there are substan- 


$\begin{aligned} & \text { Abbreviations } \\ & \text { and Acronyms }\end{aligned}$
ACC/AHA = American
College of Cardiology/
American Heart Association
AR = aortic regurgitation
AS = aortic stenosis
AVA = aortic valve area
AVR = aortic valve
replacement
CAD = coronary artery
disease
ESC = European Society of
Cardiology
LV = left ventricular
MR = mitral regurgitation
MS = mitral stenosis
MVA = mitral valve area
PPM = valve prosthesis-
patient mismatch

tial and rapid changes in heart rate and loading conditions. On the other hand, supine exercise is not as physiologic as is treadmill exercise, and the equipment is not nearly as widely available as is the treadmill.

\section{AS}

Asymptomatic patients with severe AS. The onset of symptoms in patients with severe AS represents a clear indication for aortic valve replacement (AVR) $(1,2)$. Exercise testing clearly has no role, and is contraindicated in patients with definite cardiac symptoms or symptoms that are highly suspicious. On the other hand, it is apparent that some patients, especially elderly patients, may ignore or not report mild dyspnea and fatigue, which are difficult to differentiate from the effects of aging or deconditioning. Patients also may reduce their level of physical activity to avoid or minimize symptoms. The principal role of exercise testing is to unmask symptoms or abnormal blood pressure responses in patients with AS who claim to be asymptomatic.

Numerous studies have shown that exercise testing, with appropriate physician supervision and close monitoring of the electrocardiogram and blood pressure, is safe in patients without apparent symptoms $(10-15)$ and that the results can identify a subset of patients with a high likelihood of death or symptom onset over the next 1 to 2 years (13-15). Both the ACC/AHA and the ESC guidelines $(1,2)$ support the role of exercise testing in asymptomatic AS patients, with recommendations that AVR be considered in those with exercise-induced symptoms or abnormal blood pressure responses. The strength of this recommendation differs between the 2 guidelines, with a Class IIb recommendation from the ACC/AHA compared with Class I (symptoms) and Class IIa (abnormal blood pressure) recommendations from the ESC. The divergent strengths of these recommendations arise from the lack of definitive evidence from prospective clinical trials and the consensus of 2 different writing groups in interpreting the available data. For example, it is often difficult to ascertain in aging and deconditioned patients with AS whether symptoms on treadmill testing truly represent cardiac symptoms. In addition, physicians may have a lower threshold for referring a patient for AVR after a treadmill test in which the patient had impaired exercise tolerance, presumed symptoms, or an abnormal blood pressure response compared with patients with excellent exercise capacity and a normal blood pressure response. This could result in a post-test referral bias in studies of exercise testing in AS, in which patients with abnormal exercise results are preferentially referred to AVR.

The role of exercise echocardiography in asymptomatic patients with AS is less clear because this has not been studied extensively $(16,17)$. A recent study (17) investigating 69 asymptomatic patients with severe AS (aortic valve area $[\mathrm{AVA}]<1.0 \mathrm{~cm}^{2}$ ) has shown that an increase in the mean aortic valve pressure gradient of $18 \mathrm{~mm} \mathrm{Hg}$ or more during exercise was an independent predictor of symptom onset during the 15-month mean follow-up period, as were an AVA $<0.75 \mathrm{~cm}^{2}$ and abnormal exercise results (symptoms, ST-segment depression, or $<20 \mathrm{~mm} \mathrm{Hg}$ increase in blood pressure). This increase in mean pressure gradient during exercise reflects the presence of fixed valve stenosis with limited valve compliance (18). Stress echocardiography also provides assessment of the LV functional response to exercise $(19,20)$, with evidence suggesting that patients with limited LV functional reserve (those with a lower increase in ejection fraction) are at increased risk for untoward events (20). Whether an increase in the mean aortic valve pressure gradient and/or a limited increase in ejection fraction should be considered criteria for early elective surgery requires additional investigation.

Aortic valve stenosis with low-flow, low-gradient, and $\mathbf{L V}$ dysfunction. In contrast to patients with severe $A S$ and preserved LV function, there seems to be a well-defined role of stress echocardiography in patients with LV dysfunction (21-27) (Fig. 1). Patients with anatomically severe AS and LV systolic dysfunction (ejection fraction <40\%) often present with a relatively low-pressure gradient, such as a mean gradient of 30 to $40 \mathrm{~mm} \mathrm{Hg}$ or less. These patients represent a diagnostic challenge because it is often difficult to differentiate them from other patients with a primary cardiomyopathic process and a thickened but nonstenotic aortic valve producing an outflow murmur. This latter condition is often termed pseudosevere AS. In true severe AS, the small and relatively fixed AVA contributes to an increase in afterload, a decrease in ejection fraction, and a reduction stroke volume. In pseudosevere AS, the predominant factor is myocardial disease, and the severity of AS is overestimated on the basis of AVA because there is incomplete opening of the valve caused by reduction in the opening force generated by the weakened ventricle. In both situations, the low-flow state and low-pressure gradient contribute to a calculated AVA that meets criteria for severe AS at rest $\left(\leq 1.0 \mathrm{~cm}^{2}\right)$ (Fig. 1). Hence, the resting echocardiogram does not distinguish between these 2 situations. Yet, this distinction is essential because patients with true severe AS and poor LV function will generally benefit significantly from AVR, whereas the patients with pseudosevere AS will not and may also have a higher risk of perioperative mortality.

The main objective of dobutamine stress echocardiography in the context of low-flow AS is to increase the transvalvular flow rate while not inducing myocardial ischemia. Side effects are not infrequent with full-dose dobut- 


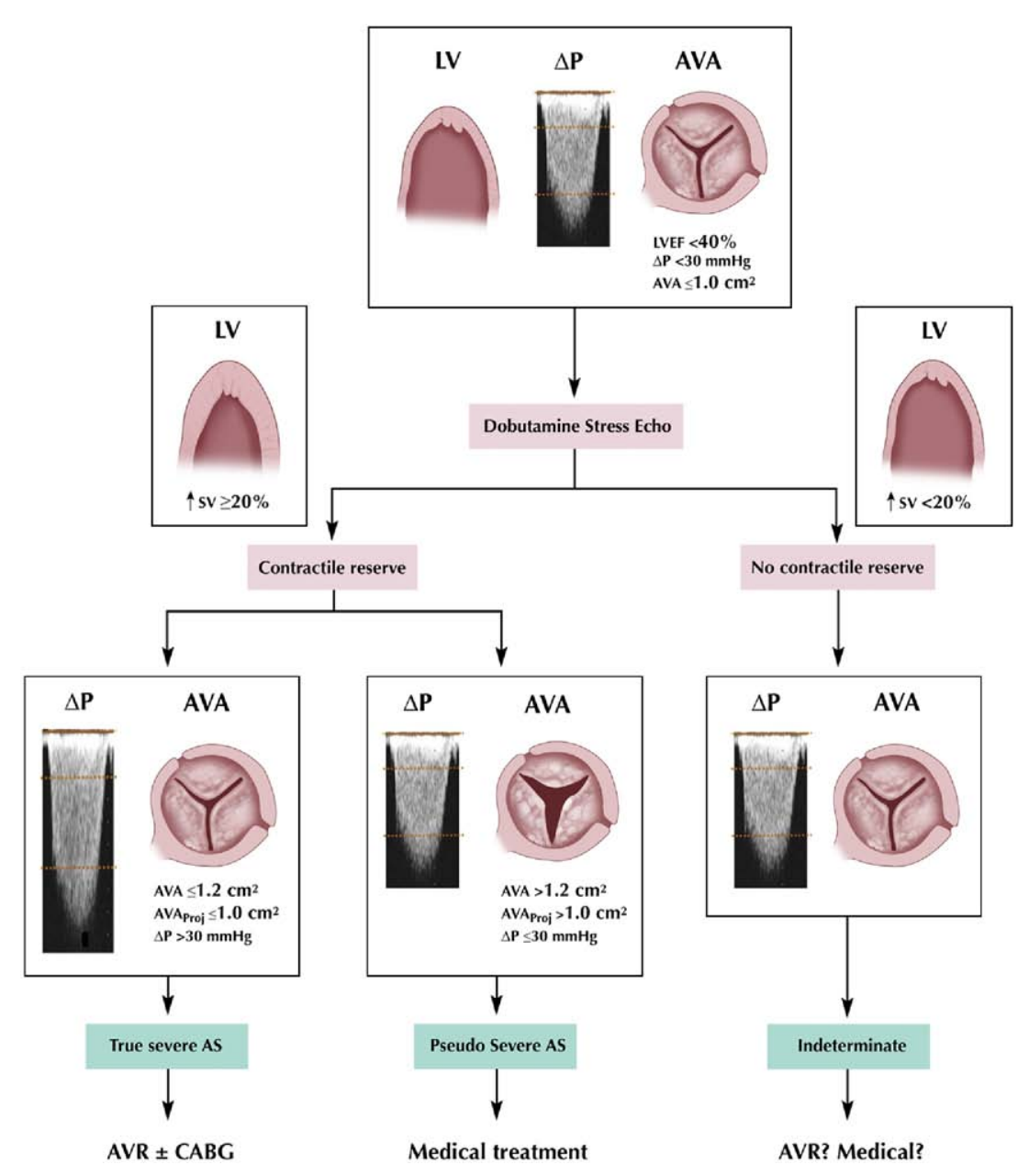

Figure 1 Decision Making in Low-Flow, Low-Gradient AS

The results of dobutamine stress echocardiography aid in decision making in patients with low-flow aortic stenosis (AS) when dobutamine elicits contractile reserve. Management decisions are more difficult when contractile reserve is absent. Contractile reserve is defined as an increase in stroke volume (SV) $\geq 20 \%$ using the criteria of Nishimura et al. (24) and Monin et al. (25). When contractile reserve is elicited, patients with true severe AS manifest an increase in transvalvular pressure gradient $(\triangle P)$ with a low calculated aortic valve area (AVA). One can also determine the projected AVA at a standardized normal flow rate (AVA $A_{\text {proj }}$ ). An AVA $A_{\text {proj }} \leq 1.0 \mathrm{~cm}^{2}$ is considered an indicator of true severe stenosis (30). Figure illustration by Rob Flewell. AVR = aortic valve replacement; CABG = coronary artery bypass graft surgery.

amine in unselected patients with normal or moderately reduced $\mathrm{LV}$ ejection fraction $(9,28)$ and can occur in up to $20 \%$ of patients with low-flow, low-gradient AS (29). Arrhythmias are the most frequent serious adverse reactions. Tachyarrhythmias (including ventricular fibrillation) can arise from ischemia or ischemia-independent direct arrhythmogenic effects of adrenergic stimulation, and bradyarrhythmias (including cardiac asystole) can result from a vasodepressor reflex triggered by LV mechanoreceptor stimulation. Both mechanisms are magnified by LV hypertrophy $(28,29)$. Hence, a low-dose protocol (i.e., up to $20 \mu \mathrm{g} / \mathrm{kg} /$ $\mathrm{min}$ ) should be used in these patients. Moreover, it is preferable to use longer dobutamine stages (5 to $8 \mathrm{~min}$ instead of the 3 to 5 min generally used for the detection of ischemic heart disease) to ensure that the patient is in a steady-state condition during Doppler echocardiography data acquisition and before proceeding to the next stage.
The gradual increments in dobutamine dose are also helpful in preventing rapid increases in heart rate that may predispose to myocardial ischemia, because ischemic myocardial dysfunction may override the inotropic effect, thereby limiting the increase in transvalvular flow.

The dobutamine stress approach is based on the concept that patients who have pseudosevere AS will show an increase in the AVA and little change in the transvalvular gradient in response to the increase in transvalvular flow rate (21) (Fig. 1). Although the dichotomization of patients into 2 categories (true severe or pseudosevere AS) is convenient, it is an oversimplification, and the classification of the individual patient may not always be straightforward. The changes in gradient and AVA during dobutamine stress depend largely on the magnitude of the flow augmentation achieved, which may vary considerably from one patient to another. Therefore, the AVA and gradient are measured at 
flow conditions that may differ dramatically from one patient to another, and the use of these indexes, which are not normalized with respect to the flow increase, may lead to misclassification of stenosis severity in some patients. To overcome this limitation, the investigators of the TOPAS (Truly or Pseudo Severe Aortic Stenosis) multicenter study (30) have proposed a new echocardiographic parameter: the projected AVA at a standardized normal flow rate. A projected AVA $\leq 1.0 \mathrm{~cm}^{2}$ is considered an indicator of true severe stenosis (Fig. 1) (30).

Assessment of functional reserve. Patients identified as having true severe AS and functional reserve, defined as the ability to increase stroke volume with dobutamine by $20 \%$ or more (25), have a much better outcome with AVR than with medical therapy $(26,27)$. Patients with a lack of LV functional reserve have been shown to have a poor prognosis with either medical or surgical management (25), but as a group they may also benefit from AVR $(27,31)$. In other words, once true severe AS has been documented, AVR might be reasonable even in the absence of LV functional reserve, although decisions in these high-risk patients must be individualized in the absence of clear guidelines.

In patients with low-flow, low-gradient $\mathrm{AS}$, dobutamine stress echocardiography has received a Class IIa recommendation in the ACC/AHA guidelines, with Level of Evidence: $B$ (1). This recommendation comes with the caveat that dobutamine stress testing in patients with AS should be performed only in centers with experience in pharmacological stress testing and with an experienced cardiologist in attendance.

Assessment of CAD and hibernating myocardium. The other potential role of dobutamine stress echocardiography in patients with $\mathrm{AS}$ and impaired $\mathrm{LV}$ function is the detection of underlying $\mathrm{CAD}$, because infarcted or hibernating myocardium may be responsible in large part for the contractile dysfunction in many patients. In such patients, revascularization has the potential to improve $\mathrm{LV}$ function and clinical outcomes $(32,33)$. However, this situation can represent a diagnostic challenge in patients with AS because multivessel $\mathrm{CAD}$ may induce global LV dysfunction, and conversely, regional wall motion abnormalities may occur in the absence of CAD (34). Moreover, lack of contractile reserve on dobutamine stress echocardiography may also be related to $\mathrm{LV}$ afterload mismatch, independent of the presence of CAD. These factors may explain why an important proportion of patients with no contractile reserve nonetheless show an improvement in LV ejection fraction after aortic valve replacement with or without revascularization (27). The specificity of stress-induced ST-segment changes and reversible perfusion abnormalities for predicting epicardial coronary artery stenosis is very low in patients with AS because alterations in coronary flow reserve linked to LV hypertrophy and microvascular disease may be present independent of $\mathrm{CAD}$ at the epicardial level (35). Thus, in these complex patients coronary angiography (invasive or noninvasive) remains the diagnostic standard.

\section{Aortic Regurgitation (AR)}

The development of symptoms has important prognostic implications in patients with AR. Natural history studies indicate that symptomatic patients have an excessive mortality rate compared with asymptomatic patients (36), and the severity of pre-operative symptoms is a strong determinant of survival after AVR (37). As with patients with AS, exercise testing may elicit symptomatic responses in patients with $\mathrm{AR}$ who are apparently asymptomatic based on the medical history, thus identifying candidates for surgery. In addition, pre-operative exercise capacity in patients with AR and LV systolic dysfunction, together with duration of pre-operative LV dysfunction, is helpful in predicting survival and recovery of function after AVR (38).

The additional value of stress imaging in patients with AR is unclear. The observed magnitude of change in ejection fraction or stroke volume from rest to exercise is related not only to myocardial contractile function but also to severity of volume-overload and exercise-induced changes in pre-load and peripheral resistance (1). The validity of stress echocardiography in predicting outcome of patients with asymptomatic AR is limited by the small number of available studies $(39,40)$ compared with the more extensive and consistent experience with exercise radionuclide angiography (41-44). With the sparse data supporting the incremental prognostic value of stress echocardiography, this specific application is not recommended for routine clinical use (1).

\section{Mitral Stenosis (MS)}

A resting transthoracic echocardiogram is usually sufficient to guide management in asymptomatic patients with mild to moderate MS and in symptomatic patients with severe MS who are candidates for either percutaneous balloon valvuloplasty or surgical mitral valve repair or replacement. Management considerations are less clear in asymptomatic patients with severe MS and in symptomatic patients with only mild to moderate MS at rest, and in these 2 groups of patients exercise testing can provide critical information on functional capacity and exercise-induced symptoms. Stress echocardiography provides added value when more detailed assessment of valve function and its hemodynamic consequences is needed, particularly in the asymptomatic patient and the patient in whom symptoms and Doppler findings at rest are discordant.

In asymptomatic patients with severe MS (mean gradient $>10 \mathrm{~mm} \mathrm{Hg}$ and mitral valve area [MVA] $<1.0 \mathrm{~cm}^{2}$ ), or symptomatic patients with moderate MS (mean gradient of 5 to $10 \mathrm{~mm} \mathrm{Hg}$ and MVA of 1.0 to $1.5 \mathrm{~cm}^{2}$ ), the measurement of pulmonary artery pressures (measured from the tricuspid regurgitant velocity) during exercise or dobutamine stress echocardiography can help distinguish those who could benefit from valvuloplasty or valve replacement from those who should be maintained on medical therapy 
$(1,45,46)$. As is the case with the aortic valve, the transmitral valve pressure gradient is related to the MVA. However, it should be emphasized that the transmitral gradient is much more sensitive to heart rate than is the transaortic gradient and that the degree of this heart rate sensitivity may vary extensively from one patient to another. Moreover, for a given MVA, patients with reduced atrioventricular compliance show a more pronounced increase in pulmonary arterial pressure during exercise or dobutamine than those with normal compliance $(45,47)$. Hence, in some patients determined to have only moderate MS at rest, the physiologic effects of heart rate sensitivity and atrioventricular compliance can produce exercise-induced pulmonary hypertension and exertional dyspnea. Because the resting values of transmitral gradient and pulmonary arterial pressure do not necessarily reflect the actual severity of the disease, stress echocardiography may provide the necessary clues in determining the severity of MS, assessing its hemodynamic impact, and explaining exercise-induced symptoms.

The current ACC/AHA guidelines have given a Class I recommendation (Level of Evidence: C) for stress echocardiography in patients with MS and discordance between symptoms and stenosis severity (1). The threshold values proposed by the ACC/AHA guidelines (1) for consideration for intervention are a mean transmitral pressure gradient $>15 \mathrm{~mm} \mathrm{Hg}$ during exercise or a peak pulmonary artery systolic pressure $>60 \mathrm{~mm} \mathrm{Hg}$ during exercise (Fig. 2). In patients with pulmonary artery pressures or valve gradients above these values, percutaneous balloon valvotomy or surgical intervention is recommended, even for patients with apparently moderate MS at rest $(1,7,9)$. There are important caveats in applying these recommendations in clinical practice because they are all based on a level $\mathrm{C}$ weight of evidence, and the proposed cutoff values remain arbitrary and consensus driven and not supported by evidence of improved outcomes. Therefore, this represents another area in which further clinical research is needed.

\section{Mitral Regurgitation (MR)}

Degenerative MR. The severity of degenerative MR can be reliably assessed by resting color-flow Doppler echocardiography with the use of semiquantitative or quantitative methods $(1,2,48)$. Such information is useful to predict the development of LV dysfunction and of symptoms (49). Presently, there is an important ongoing controversy regarding whether asymptomatic patients with severe MR should undergo early elective mitral valve repair (49-52). In selected patients with MR, exercise testing may aid in this critical management decision.

Exercise capacity itself is a predictor of the development of symptoms or LV dysfunction in asymptomatic patients with MR (53). In asymptomatic patients with severe MR, exercise stress echocardiography may help identify patients with unrecognized symptoms or subclinical latent LV dysfunction.

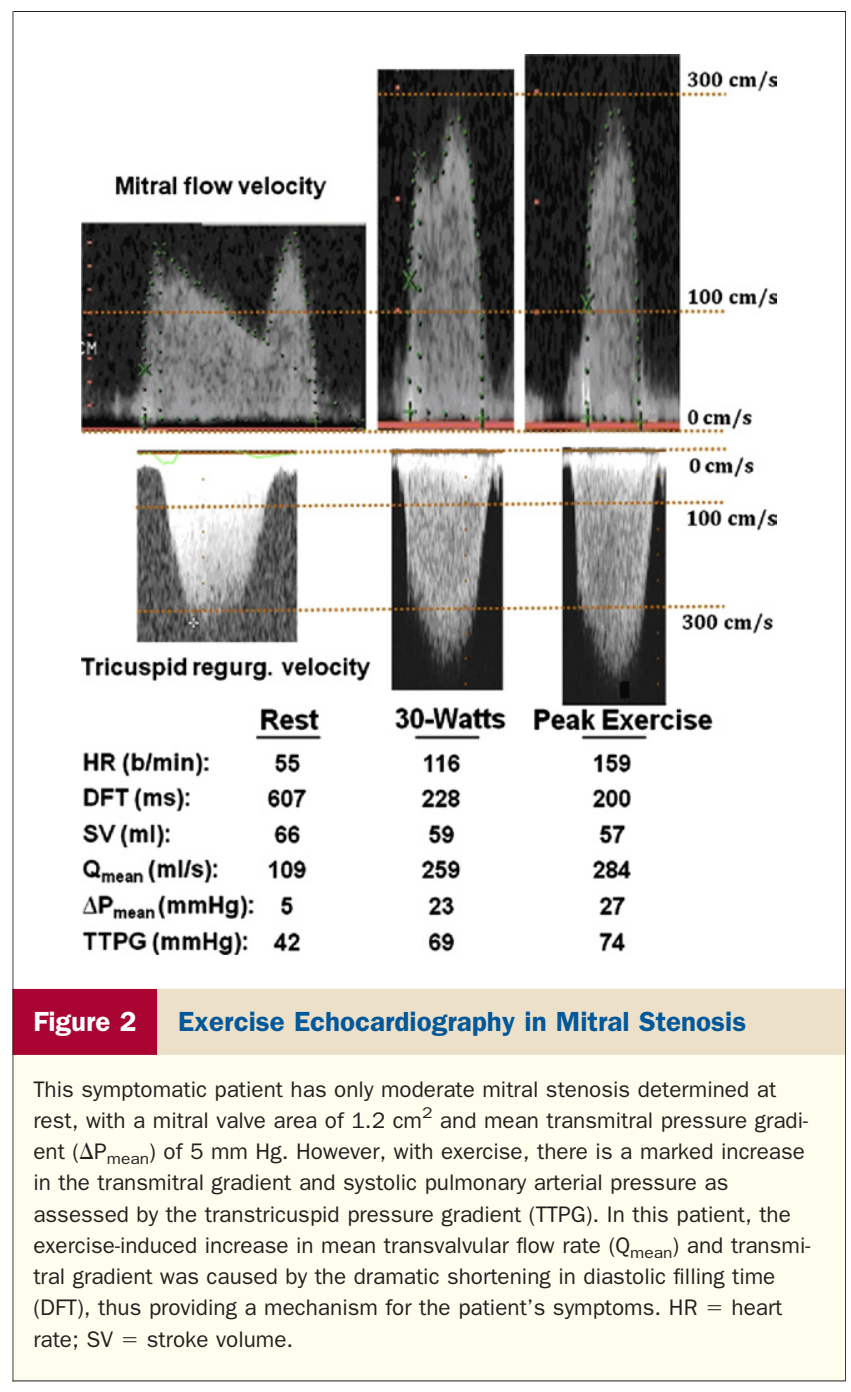

In symptomatic patients in whom the severity of MR is estimated to be only mild at rest, exercise echocardiography may be useful in elucidating the cause of symptoms by determining whether the severity of MR increases or pulmonary arterial hypertension develops during exercise (54). It is noteworthy that the data supporting this concept were derived in patients with rheumatic MR, and the data supporting this application for degenerative MR are limited. Moreover, data supporting this application in asymptomatic patients are limited. However, worsening of MR severity, a marked increase in pulmonary arterial pressure, impaired exercise capacity, and the occurrence of symptoms during exercise echocardiography can be useful findings for identifying a subset of apparently asymptomatic patients at higher risk who may benefit from early surgery. A pulmonary artery systolic pressure $>60 \mathrm{~mm} \mathrm{Hg}$ during exercise has been suggested as a threshold value above which asymptomatic patients with severe MR might be referred for surgical valve repair $(1,8)$. This application of stress echocardiography is rated as a Class IIa recommendation with Level of Evidence: C (1). Recommendations for early surgery in asymptomatic patients should only be made in those patients who 
are candidates for mitral valve repair and in experienced centers in which there is expertise both in noninvasive evaluation and in surgical correction, with a high likelihood (>90\%) of successful mitral repair without residual MR (1). Valve replacement has particularly serious negative consequences for asymptomatic patients. Large prospective studies are needed to establish the usefulness of stress echocardiography for risk stratification and clinical decision making in degenerative MR.

The spectrum of $\mathrm{LV}$ responses to exercise stress in patients with MR is not dissimilar to that described for patients with AR (55), but the prognostic impact of this functional heterogeneity remains unsettled, and the importance of LV functional reserve in MR as assessed by changes in $L V$ ejection fraction remains to be defined. A recent report, using 2-dimensional speckle tracking of myocardial deformation, has shown that reduced LV longitudinal functional reserve with exercise predicts midterm impairment in LV function in medically-treated patients with $M R$ as well as post-operative $L V$ dysfunction in patients who have undergone surgery for MR (56). This novel application of stress echocardiography is the subject of ongoing investigation.

Ischemic MR. MR is a common feature of ischemic LV systolic dysfunction (57-59). Patients with ischemic MR have more severe $L V$ dysfunction compared with patients without associated $\mathrm{MR}$, and the available data indicate that MR also confers a greater mortality risk and a greater risk of developing overt heart failure (57-60). MR arises in chronic $\mathrm{CAD}$ from global and regional LV remodeling (apical and posterior displacement of papillary muscles) leading to papillary muscle displacement, tenting of the mitral valve leaflets, and loss of systolic annular contraction (61-63). Hence, ischemic MR is primarily a disease of the LV myocardium, and therapies that produce beneficial reverse LV remodeling, such as myocardial revascularization (64), beta-blocker therapy (65), and cardiac resynchronization (66-68), have the potential to reduce or eliminate MR. In the case of revascularization, this can usually only be achieved with concomitant mitral valve repair with restrictive annuloplasty or mitral valve replacement $(1,2,69,70)$.

A principal role of stress echocardiography in ischemic $\mathrm{MR}$ is to determine the extent of dysfunctional but viable hibernating myocardium. Identification of viable myocardium with pharmacologic stress echocardiography predicts the likelihood of recovery of function and beneficial reverse remodeling with revascularization (64,71-73), beta-blockade (74), and cardiac resynchronization therapy (75). Changes in MR severity can also be observed during dobutamine stress testing for myocardial viability, but the direct effect of dobutamine on loading conditions is a major confounding variable. Moreover, the role of surgical intervention targeted to eliminate MR remains uncertain because there is a high rate of recurrent $\mathrm{MR}$ related to ongoing $\mathrm{LV}$ remodeling (76), and long-term survival of patients with ischemic MR
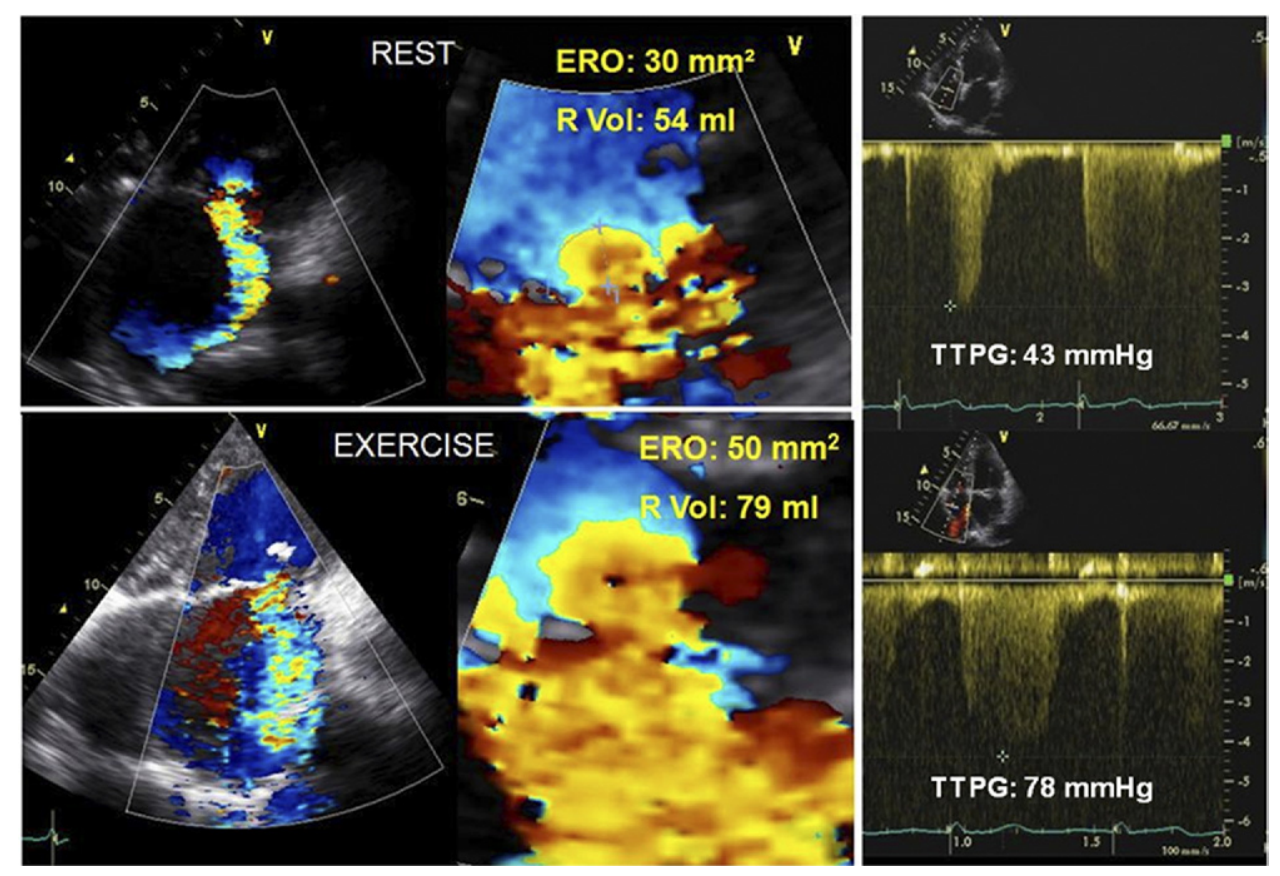

Figure 3 Exercise Echocardiography in Ischemic Mitral Regurgitation

Apical 4-chamber views of color-flow Doppler and proximal flow-convergence region (left panels) are shown in a patient with ischemic mitral regurgitation (MR) along with the systolic tricuspid regurgitation velocity (right panel). With exercise, there is a major increase in both the severity of mitral regurgitation and the estimated pulmonary artery systolic pressure. ERO = effective regurgitant orifice measured by the proximal isovelocity surface area; $\mathrm{R}$ Vol $=$ regurgitant volume; TTPG $=$ systolic transtricuspid pressure gradient. 
is poor whether treated medically or surgically $(77,78)$, in large part related to the severity of LV dysfunction.

The role of Doppler echocardiography in assessing dynamic changes in MR severity with exercise, to identify higher-risk patients for surgery, is the subject of current investigation. The magnitude of ischemic MR varies dynamically in accordance with changes in loading conditions, $\mathrm{LV}$ regional wall motion, and annular size and the balance of tethering versus closing forces applied on the mitral valve leaflets (79). Hence, the severity of MR assessed by Doppler echocardiography at rest does not necessarily reflect the severity of MR that develops during exercise. Exercise stress echocardiography has been shown to unmask hemodynamically significant $M R$ in patients with ischemic $L V$ systolic dysfunction and only mild to moderate MR at rest (Fig. 3), and in doing so to identify patients at higher risk for heart failure and death (80-82). The magnitude of increase in effective regurgitant orifice during exercise often cannot be predicted from the resting effective regurgitant orifice.

Pierard and Lancellotti $(82,83)$ have proposed that exercise Doppler echocardiography can provide useful information in the following patients with ischemic MR: 1) those with exertional dyspnea out of proportion to the severity of MR or the degree of LV dysfunction at rest; 2) those in whom acute pulmonary edema occurs without an obvious cause; and 3) those with moderate MR before surgical revascularization. A large prospective multicenter registry of surgery in patients with ischemic MR is underway, designed to assess the role of exercise echocardiography in identifying determinants of adverse outcomes, progressive LV remodeling, and efficacy of treatment (84).

\section{Prosthetic Heart Valves}

Echocardiography is the method of choice for evaluating prosthetic valve function $(1,2)$. Because most prosthetic valves are inherently stenotic, the effective orifice area of a prosthetic valve is occasionally too small in relation to body size, a phenomenon known as valve prosthesis-patient mismatch (PPM) $(85,86)$. In the aortic position, PPM is considered moderate when the indexed effective orifice area is $\leq 0.85 \mathrm{~cm}^{2} / \mathrm{m}^{2}$ and severe when it is $\leq 0.65 \mathrm{~cm}^{2} / \mathrm{m}^{2}$ (87). In the mitral position, the cutoff values are 1.2 and 0.9 $\mathrm{cm}^{2} / \mathrm{m}^{2}$, respectively. PPM has been linked to impaired exercise capacity, suboptimal symptomatic improvement, incomplete regression of LV hypertrophy and pulmonary hypertension, and increased cardiac events and mortality (88-93). PPM is a frequent cause of increased transprosthetic gradient $(86,94)$. It is important to differentiate this condition from acquired prosthetic stenosis, which may result from leaflet calcification, pannus overgrowth, or thrombus formation.

Because normally and abnormally functioning prostheses can produce similar estimated gradients at rest by transthoracic echocardiography, stress echocardiography may be valuable in confirming or excluding the presence of hemo- dynamically significant prosthetic valve stenosis or PPM, especially when there is discordance between the patient's symptomatic status and the prosthetic valve hemodynamics measured at rest $(87,95,96)$. In contrast to a normally functioning and well-matched prosthesis (including a bileaflet mechanical valve with a localized high gradient at rest), a stenotic prosthetic valve or PPM is generally associated with impaired exercise capacity and a marked increase in gradient with exercise, often with pulmonary arterial hypertension $(97,98)$. A disproportionate increase in transvalvular gradient $(>20 \mathrm{~mm} \mathrm{Hg}$ for aortic prostheses or $>12 \mathrm{~mm} \mathrm{Hg}$ for mitral prostheses) generally indicates severe prosthesis dysfunction or PPM (Fig. 4). High resting and stress gradients occur more often with smaller ( $\leq 21$ for aortic

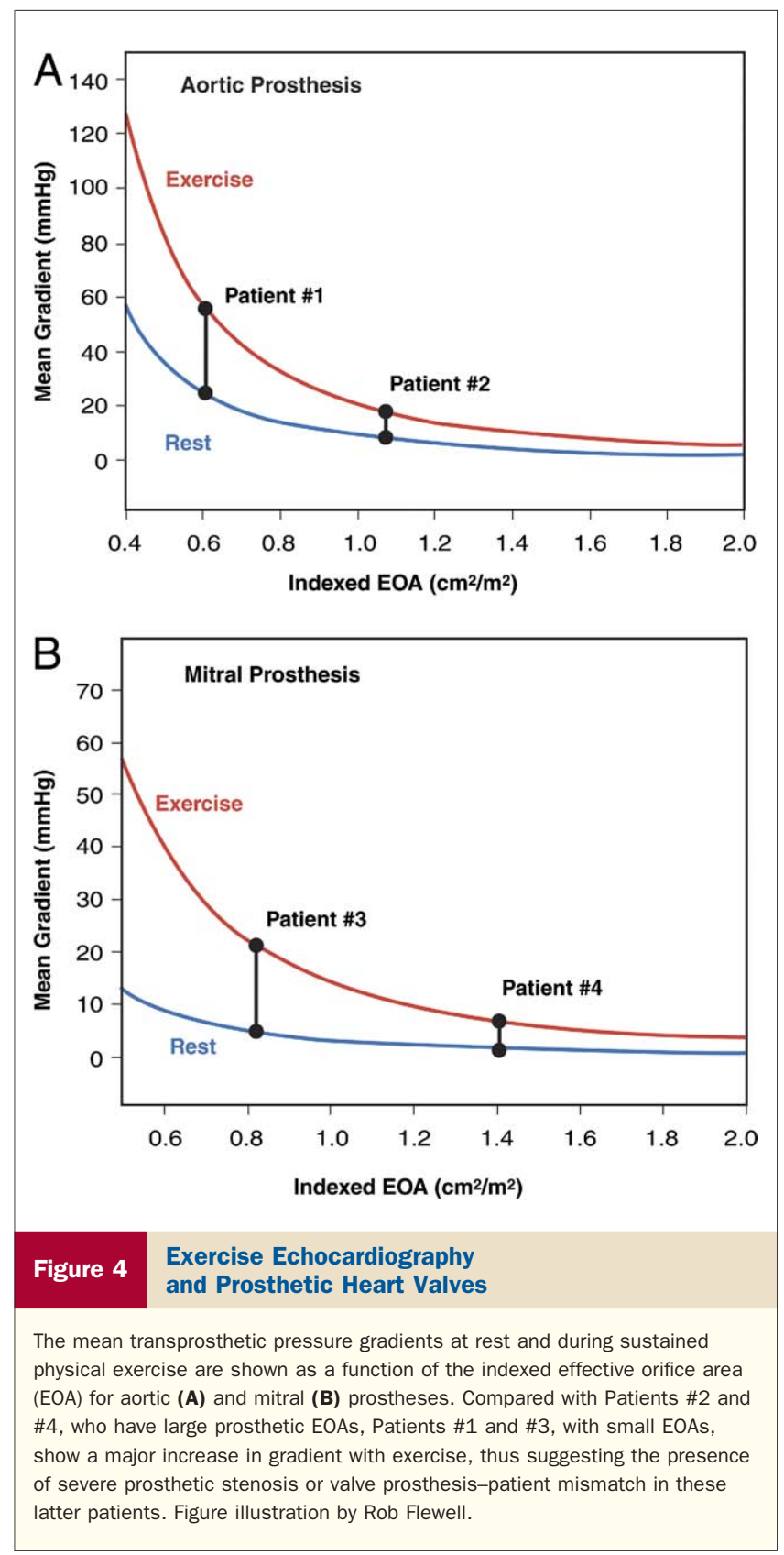


and $\leq 25$ for mitral) rather than larger-sized prostheses, and mismatched rather than nonmismatched prostheses.

\section{Conclusions}

Exercise testing has an established role in the evaluation of patients with valvular heart disease and can aid significantly in clinical decision making. Stress echocardiography has emerged as an important component of stress testing in which the noninvasive assessment of dynamic changes in valve function, ventricular function, and hemodynamics can be coupled with assessment of exercise capacity and symptomatic responses. Stress echocardiography has the advantages of its wide availability, low cost, and versatility for the assessment of disease severity $(1,2,8,9)$. Hence, together with exercise capacity and symptomatic responses to exercise, it provides the clinician with diagnostic and prognostic information that can contribute to subsequent clinical decisions.

Guidelines, restricted to the rigors of evidence-based data, may underemphasize the utility of exercise testing in valve disease. Nevertheless, it is also true that most of the guidelines and society recommendations are based on Level of Evidence: $\mathrm{C}$, that is, the consensus of the writing committees in the absence of a firm evidence base (99). Convincing evidence is lacking that the results of stress echocardiography lead to clinical decisions that result in better outcomes. Prospective large-scale, and when possible, randomized (medical vs. interventional treatment) outcome studies are needed at this point to support more evidencebased rather than consensus-based treatment strategies in patients with valvular heart disease.

Reprint requests and correspondence: Dr. Robert O. Bonow, Division of Cardiology, Northwestern University Feinberg School of Medicine, 676 North St. Clair, Suite 600, Chicago, Illinois 60611. E-mail: r-bonow@northwestern.edu.

\section{REFERENCES}

1. Bonow RO, Carabello BA, Chatterjee K, et al. ACC/AHA 2006 guidelines for the management of patients with valvular heart disease: a report of the American College of Cardiology/American Heart Association Task Force on Practice Guidelines (Writing Committee to Revise the 1998 Guidelines for the Management of Patients With Valvular Heart Disease). J Am Coll Cardiol 2006;48:e1-148.

2. Vahanian A, Baumgartner H, Bax J, et al., for the Task Force on the Management of Valvular Heart Disease of the European Society of Cardiology. Guidelines on the management of valvular heart disease. Eur Heart J 2007;28:230-68.

3. Picano E. Stress echocardiography: from pathophysiological toy to diagnostic tool. Point of view. Circulation 1992;85:1604-12.

4. Gibbons RJ, Abrams J, Chatterjee K, et al. ACC/AHA 2002 guideline update for the management of patients with chronic stable angina: summary article: a report of the American College of Cardiology/ American Heart Association Task Force on Practice Guidelines (Committee on the Management of Patients With Chronic Stable Angina). J Am Coll Cardiol 2003;41:159-68.

5. Fox K, Garcia MA, Ardissino D, et al., for the Task Force on the Management of Stable Angina Pectoris of the European Society of Cardiology. Guidelines on the management of stable angina pectoris: executive summary. Eur Heart J 2006;27:1341-8.
6. Hatazawa S, Wakahara H, Sasaki S, et al. Exercise echocardiographic evaluation of postoperative cardiac function in patients undergoing open mitral commissurotomy. Nippon Kyobu Geka Gakkai Zasshi 1985;33:981-8.

7. Sagar KB, Wann LS, Paulson WJ, Lewis S. Role of exercise Doppler echocardiography in isolated mitral stenosis. Chest 1987;92:27-30.

8. Pellikka PA, Nagueh SF, Elhendy AA, Kuehl CA, Sawada SG. American Society of Echocardiography recommendations for performance, interpretation, and application of stress echocardiography. J Am Soc Echocardiogr 2007;20:1021-41.

9. Sicari R, Niohyannopoulos P, Evangelista A, et al. Stress echocardiography consensus statement of the European Association of Echocardiography. Eur J Echocardiogr 2008;9:415-37.

10. Clyne CA, Arrighi JA, Maron BJ, Dilsizian V, Bonow RO, Cannon RO III. Systemic and left ventricular responses to exercise stress in asymptomatic patients with valvular aortic stenosis. Am J Cardiol 1991;68:1469-76.

11. Otto CM, Pearlman AS, Kraft CD, Miyake-Hull CY, Burwash IG, Gardner CJ. Physiologic changes with maximal exercise in asymptomatic valvular aortic stenosis assessed by Doppler echocardiography. J Am Coll Cardiol 1992;20:1160-7.

12. Otto CM, Burwash IG, Legget ME, et al. Prospective study of asymptomatic valvular aortic stenosis: clinical, echocardiographic, and exercise predictors of outcome. Circulation 1997;95:2262-70.

13. Amato MC, Moffa PJ, Werner KE, et al. Treatment decision in asymptomatic aortic valve stenosis: role of exercise testing. Heart 2001;86:381-6.

14. Alborino D, Hoffmann JL, Fournet PC, et al. Value of exercise testing to evaluate the indication for surgery in asymptomatic patients with valvular aortic stenosis. J Heart Valve Dis 2002;11:204-9.

15. Das $\mathrm{P}$, Rimington $\mathrm{H}$, Chambers J. Exercise testing to stratify risk in aortic stenosis. Eur Heart J 2005;26:1309-13.

16. Otto CM, Pearlman AS, Kraft CD, Miyake-Hull CY, Burwash IG, Gardner CJ. Physiologic changes with maximal exercise in asymptomatic valvular aortic stenosis assessed by Doppler echocardiography. J Am Coll Cardiol 1992;20:1160-7.

17. Lancellotti P, Lebois F, Simon M, Tombeux C, Chauvel C, Pierard LA. Prognostic importance of quantitative exercise Doppler echocardiography in asymptomatic valvular aortic stenosis. Circulation 2005; 112 Suppl I:I377-82.

18. Leurent G, Donal E, de Place C, et al. Argument for a Doppler echocardiography during exercise in assessing asymptomatic patients with severe aortic stenosis. Eur J Echocardiogr 2009;10:69-73.

19. Lancellotti P, Karsera D, Tumminello G, Lebois F, Piérard LA. Determinants of an abnormal response to exercise in patients with asymptomatic valvular aortic stenosis. Eur J Echocardiogr 2008;9: 338-43.

20. Maréchaux S, Ennezat PV, LeJemtel TH, et al. Left ventricular response to exercise in aortic stenosis: an exercise echocardiographic study. Echocardiography 2007;24:955-9.

21. Grayburn PA. Assessment of low-gradient aortic stenosis with dobutamine. Circulation 2006;113:604-6.

22. deFilippi CR, Willett DL, Brickner ME, et al. Usefulness of dobutamine echocardiography in distinguishing severe from non severe valvular aortic stenosis in patients with depressed left ventricular function and low transvalvular gradients. Am J Cardiol 1995;75: 191-4.

23. Schwammenthal E, Vered Z, Moshkowitz Y, et al. Dobutamine echocardiography in patients with aortic stenosis and left ventricular dysfunction: predicting outcome as a function of management strategy. Chest 2001;119:1766-77.

24. Nishimura RA, Grantham JA, Connolly HM, Schaff HV, Higano ST, Holmes DR Jr. Low-output, low-gradient aortic stenosis in patients with depressed left ventricular systolic function: the clinical utility of the dobutamine challenge in the catheterization laboratory. Circulation 2002;106:809-13.

25. Monin JL, Monchi M, Gest V, Duval-Moulin AM, Dubois-Rande JL, Gueret P. Aortic stenosis with severe left ventricular dysfunction and low transvalvular pressure gradients: risk stratification by low dose dobutamine echocardiography. J Am Coll Cardiol 2001;37:2101-7.

26. Monin JL, Quere JP, Monchi M, et al. Low-gradient aortic stenosis: operative risk stratification and predictors for long-term outcome: a multicenter study using dobutamine stress hemodynamics. Circulation 2003;108:319-24. 
27. Quere JP, Monin JL, Levy F, et al. Influence of preoperative left ventricular contractile reserve on postoperative ejection fraction in low-gradient aortic stenosis. Circulation 2006;113:1738-44.

28. Picano E, Mathias W Jr., Pingitore A, Bigi R, Previtali M, for the EDIC Study Group. Safety and tolerability of dobutamine-atropine stress echocardiography: a prospective, large-scale, multicenter trial. Lancet 1994;344:1190-2.

29. Bountioukos M, Kertai MD, Schinkel AF, et al. Safety of dobutamine stress echocardiography in patients with aortic stenosis. J Heart Valve Dis 2003;12:441-6.

30. Blais C, Burwash IG, Mundigler G, et al. The projected valve area at normal flow rate improves the assessment of stenosis severity in patients with low flow aortic stenosis: the multicenter TOPAS (Truly or Pseudo Severe Aortic Stenosis) study. Circulation 2006;113:711-21.

31. Tribouilloy C, Levy F, Rusinaru D, et al. Outcome after aortic valve replacement for low-flow/low-gradient aortic stenosis without contractile reserve on dobutamine stress echocardiography. J Am Coll Cardiol 2009;53:1865-73.

32. Rahimtoola SH. A perspective on the three large multicenter randomized clinical trials of coronary bypass surgery for chronic stable angina. Circulation 1985;72:V123-35.

33. Allman KC, Shaw LJ, Hachamovitch R, Udelson JE. Myocardial viability testing and impact of revascularization on prognosis in patients with coronary artery disease and left ventricular dysfunction: a meta-analysis. J Am Coll Cardiol 2002;39:1151-8.

34. Marwick TH. Application of stress echocardiography to the evaluation of non-coronary heart disease. Eur J Echocardiogr 2000;1:171-9.

35. Picano E, Pálinkás A, Amyot R. Diagnosis of myocardial ischemia in hypertensive patients. J Hypertens 2001;19:1177-83.

36. Dujardin KS, Enriquez-Sarano M, Schaff HV, Bailey KR, Seward JB, Tajik AJ. Mortality and morbidity of aortic regurgitation in clinical practice: a long-term follow-up study. Circulation 1999;99:1851-7.

37. Klodas E, Enriquez-Sarano M, Tajik AJ, et al. Optimizing timing of surgical correction in patients with severe aortic regurgitation: role of symptoms. J Am Coll Cardiol 1997;30:746-52.

38. Bonow RO, Dodd JT, Maron BJ, et al. Long-term serial changes in left ventricular function and reversal of ventricular dilatation after valve replacement for chronic aortic regurgitation. Circulation 1988;78: 1108-20.

39. Wahi S, Haluska B, Pasquet A, Case C, Rimmermann CM, Marwick TH. Exercise echocardiography predicts development of left ventricular dysfunction in medically and surgically treated patients with asymptomatic severe aortic regurgitation. Heart 2000;84:606-14.

40. Espinola-Zavaleta N, Gómez-Núñez N, Chávez PY, et al. Evaluation of the response to pharmacological stress in chronic aortic regurgitation. Echocardiogr 2001;18:491-6.

41. Bonow RO, Lakatos E, Maron BJ, Epstein SE. Serial long term assessment of the natural history of asymptomatic patients with chronic aortic regurgitation and normal left ventricular systolic function. Circulation 1991;84:1625-35.

42. Tornos MP, Olona M, Permanyer-Miralda G, et al. Clinical outcome of severe asymptomatic chronic aortic regurgitation: a long-term prospective follow-up study. Am Heart J 1995;130:333-9.

43. Borer JS, Hochreiter C, Herrold EM, et al. Prediction of indications for valve replacement among asymptomatic or minimally symptomatic patients with chronic aortic regurgitation and normal left ventricular performance. Circulation 1998;97:525-34.

44. Tamas E, Broqvist M, Olsson E, Franzen S, Nylander E. Exercise radionuclide ventriculography for predicting post-operative left ventricular function in chronic aortic regurgitation. J Am Coll Cardiol Img 2009;2:48-55.

45. Schwammenthal E, Vered Z, Agranat O, Kaplinsky E, Rabinowitz B, Feinberg MS. Impact of atrioventricular compliance on pulmonary artery pressure in mitral stenosis: an exercise echocardiographic study. Circulation 2000;102:2378-84.

46. Reis G, Motta MS, Barbosa MM, Esteves WA, Souza SF, Bocchi EA. Dobutamine stress echocardiography for noninvasive assessment and risk stratification of patients with rheumatic mitral stenosis. J Am Coll Cardiol 2004;43:393-401.

47. Li M, Dumesnil JG, Mathieu P, et al. Impact of valve prosthesispatient mismatch on pulmonary arterial pressure after mitral valve replacement. J Am Coll Cardiol 2005;45:1034-40.

48. Zoghbi WA, Enriquez-Sarano M, Foster E, et al. Recommendations for evaluation of the severity of native valvular regurgitation with two-dimensional and Doppler echocardiography. J Am Soc Echocardiogr 2003;16:777-802.

49. Enriquez-Sarano M, Avierinos JF, Messika-Zeitoun D, et al. Quantitative determinants of the outcome of asymptomatic mitral regurgitation. N Engl J Med 2005;352:875-83.

50. Rosenhek R, Rader F, Klaar U, et al. Outcome of watchful waiting in asymptomatic severe mitral regurgitation. Circulation 2006;113:2238-44.

51. Madaric J, Watripont $\mathrm{P}$, Bartunek J, et al. Effect of mitral valve repair on exercise tolerance in asymptomatic patients with organic mitral regurgitation. Am Heart J 2007;154:180-5.

52. Kang DH, Kim JH, Rim JH, et al. Comparison of early surgery versus conventional treatment in asymptomatic severe mitral regurgitation. Circulation 2009;119:797-804.

53. Supino PG, Borer JS, Schuleri K, et al. Prognostic value of exercise tolerance testing in asymptomatic chronic nonischemic mitral regurgitation. Am J Cardiol 2007;100:1274-81.

54. Tischler MD, Battle RW, Saha M, Niggel J, LeWinter MM. Observations suggesting a high incidence of exercise-induced severe mitral regurgitation in patients with mild rheumatic mitral valve disease at rest. J Am Coll Cardiol 1995;25:128-33.

55. Lee R, Haluska B, Leung DY, Case C, Mundy J, Marwick TH. Functional and prognostic implications of left ventricular contractile reserve in patients with asymptomatic severe mitral regurgitation. Heart 2005;91:1407-12.

56. Lancellotti P, Cosyns B, Zacharakis D, et al. Importance of left ventricular longitudinal function and functional reserve in patients with degenerative mitral regurgitation: assessment by two-dimensional speckle tracking. J Am Soc Echocardiogr 2008;21:1331-6.

57. Grigioni F, Enriquez-Sarano M, Zehr KL, Bailey KR, Tajik AJ. Ischemic mitral regurgitation: long-term outcome and prognostic implications with quantitative Doppler assessment. Circulation 2001; 103:1759-64

58. Robbins JD, Maniar PB, Cotts W, Parker MA, Bonow RO, Gheorghiade $\mathrm{M}$. Prevalence and severity of mitral regurgitation in chronic systolic heart failure. Am J Cardiol 2003;91:360-2.

59. Koelling TM, Aaronson KD, Cody RJ, Bach DS, Armstrong WF. Prognostic significance of mitral regurgitation and tricuspid regurgitation in patients with left ventricular systolic dysfunction. Am Heart J 2002;144:524-9.

60. Bursi F, Enriquez-Sarano M, Nkomo VT, et al. Heart failure and death after myocardial infarction in the community: the emerging role of mitral regurgitation. Circulation 2005;111:295-301.

61. Yiu SF, Enriquez-Sarano M, Tribouilloy C, Seward JB, Tajik AJ. Determinants of the degree of functional mitral regurgitation in patients with systolic left ventricular dysfunction: a quantitative clinical study. Circulation 2000;102:1400-6.

62. Kwan J, Shiota T, Agler DA, et al. Geometric differences of the mitral apparatus between ischemic and dilated cardiomyopathy with significant mitral regurgitation: real-time three-dimensional echocardiography study. Circulation 2003;107:1135-40.

63. Levine RA, Schwammenthal E. Ischemic mitral regurgitation on the threshold of a solution: from paradoxes to unifying concepts. Circulation 2005;112:745-58.

64. Rizzello V, Poldermans D, Boersman E, et al. Opposite patterns of left ventricular remodeling after coronary revascularization in patients with ischemic cardiomyopathy: role of myocardial viability. Circulation 2004;110:2383-8.

65. Capomolla S, Febo O, Gnemmi M, et al. $\beta$-blockade therapy in chronic heart failure: diastolic function and mitral regurgitation improvement by carvedilol. Am Heart J 2000;139:596-608.

66. St John Sutton MG, Plappert T, Abraham WT, et al. Effect of cardiac resynchronization therapy on left ventricular size and function in chronic heart failure. Circulation 2003;107:1985-90.

67. Bax JJ, Abraham T, Barold SS, et al. Cardiac resynchronization therapy. Part 2-issues during and after device implantation and unresolved questions. J Am Coll Cardiol 2005;46:2168-82.

68. Cleland JGF, Daubert JC, Erdmann E, et al. The effect of cardiac resynchronization on morbidity and mortality in heart failure. $\mathrm{N} \mathrm{Engl}$ J Med 2005;352:1539-49.

69. Prifti E, Bonacchi M, Frati G, Giunti G, Babatasi G, Sani G. Ischemic mitral valve regurgitation grade II-III: correction in patients with impaired left ventricular function undergoing simultaneous coronary revascularization. J Heart Valve Dis 2001;10:754-62. 
70. Bax JJ, Braun J, Somer ST, et al. Restrictive annuloplasty and coronary revascularization in ischemic mitral regurgitation results in reverse left ventricular remodeling. Circulation 2004;110 Suppl II:II103-8.

71. Sicari R, Picano E, Cortigiani L, et al. Prognostic value of myocardial viability recognized by low-dose dobutamine echocardiography in chronic ischemic left ventricular dysfunction. Am J Cardiol 2003;92: 1263-6.

72. Schinkel AFL, Bax JJ, Poldermans D, Elhendy A, Ferrari R, Rahimtoola SH. Hibernating myocardium: diagnosis and patient outcomes. Curr Probl Cardiol 2007;32:375-410.

73. Camici PG, Prasad SK, Rimoldi OE. Stunning, hibernation, and assessment of myocardial viability. Circulation 2008;117:103-14.

74. Seghatol FF, Shah DJ, DiLuzio S, et al. Relation between contractile reserve and improvement in left ventricular function with beta blocker therapy in patients with heart failure secondary to ischemic or idiopathic dilated cardiomyopathy. Am J Cardiol 2004;93:854-9.

75. Ypenburg C, Sieders A, Bleeker GB, et al. Myocardial contractile reserve predicts improvement in left ventricular function after cardiac resynchronization therapy. Am Heart J 2007;154:1160-5.

76. McGee EC, Gillinov AM, Blackstone EH, et al. Recurrent mitral regurgitation after annuloplasty for functional ischemic mitral regurgitation. J Thorac Cardiovasc Surg 2004;128:916-24.

77. Wu AH, Aaronson KD, Bolling SF, Pigani FD, Welxh K, Koelling TM. Impact of mitral valve annuloplasty on mortality risk in patients with mitral regurgitation and left ventricular systolic dysfunction. J Am Coll Cardiol 2005;45:381-7.

78. Mihaljevic T, Lam BK, Rajeswaran J, et al. Impact of mitral valve annuloplasty combined with revascularization in patients with functional ischemic mitral regurgitation. J Am Coll Cardiol 2007;49:2191-201.

79. Lancellotti P, Lebrun F, Piérard LA. Determinants of exerciseinduced changes in mitral regurgitation in patients with coronary artery disease and left ventricular dysfunction. J Am Coll Cardiol 2003;42:1921-8.

80. Lancellotti P, Troisfontaines P, Toussaint AC, Pierard LA. Prognostic importance of exercise-induced changes in mitral regurgitation in patients with chronic ischemic left ventricular dysfunction. Circulation 2003;108:1713-7.

81. Pierard LA, Lancellotti P. The role of ischemic mitral regurgitation in the pathogenesis of acute pulmonary edema. N Engl J Med 2004;351: $1627-34$.

82. Lancellotti P, Gérard P, Piérard LA. Long term outcome of patients with heart failure and dynamic mitral regurgitation. Eur Heart J 2005;26:1528-32.

83. Pierard LA, Lancellotti P. Stress testing in valve disease. Heart 2007;93:766-72.

84. Lancellotti P, Donal E, Cosyns B, et al. Effects of surgery on ischaemic mitral regurgitation: a prospective multicentre registry (SIMRAM registry). Eur J Echocardiogr 2008;9:26-30.

85. Rahimtoola $\mathrm{SH}$. The problem of valve prosthesis-patient mismatch. Circulation 1978;58:20-4.
86. Rahimtoola SH. Valve prosthesis-patient mismatch: an update. J Heart Valve Dis 1998;7:207-10.

87. Pibarot P, Dumesnil JG. Hemodynamic and clinical impact of prosthesis-patient mismatch in the aortic valve and its prevention. J Am Coll Cardiol 2000;36:1131-41.

88. Rahimtoola SH, Murphy E. Valve prosthesis-patient mismatch: a long-term sequela. Br Heart J 1981;45:331-5.

89. Blais C, Dumesnil JG, Baillot R, Simard S, Doyle D, Pibarot P. Impact of valve prosthesis-patient mismatch on short-term mortality after aortic valve replacement. Circulation 2003;108:983-8.

90. Ruel M, Rubens FD, Masters RG, et al. Late incidence and predictors of persistent or recurrent heart failure in patients with aortic prosthetic valves. J Thorac Cardiovasc Surg 2004;127:149-59.

91. Mohty D, Malouf JF, Girard SE, et al. Impact of prosthesis-patient mismatch on long-term survival in patients with small St. Jude medical mechanical prostheses in the aortic position. Circulation 2006;113: 420-6.

92. Magne J, Mathieu P, Dumesnil JG, et al. Impact of prosthesis-patient mismatch on survival after mitral valve replacement. Circulation 2007;115:1417-25.

93. Bleiziffer S, Eichinger WB, Hettich I, et al. Impact of prosthesispatient mismatch on exercise capacity in patients after bioprosthetic aortic valve replacement. Heart 2008;94:637-41.

94. Pibarot P, Dumesnil JG. Prosthetic heart valves: selection of the optimal prosthesis and long-term management. Circulation 2009;119: 1034-48.

95. Pibarot P, Dumesnil JG, Jobin J, et al. Hemodynamic and physical performance during maximal exercise in patients with an aortic bioprosthetic valve: comparison of stentless versus stented bioprostheses. J Am Coll Cardiol 1999;34:1609-17.

96. Pibarot P, Dumesnil JG, Jobin J, et al. Usefulness of the indexed effective orifice area at rest in predicting an increase in gradient during maximum exercise in patients with a bioprosthesis in the aortic valve position. Am J Cardiol 1999;83:542-6.

97. Tatineni S, Barner HB, Pearson AC, et al. Rest and exercise evaluation of St. Jude Medical and Medtronic Hall prostheses: influence of primary lesion, valvular type, valvular size, and left ventricular function. Circulation 1989;80 Suppl I:I16-23.

98. Hobson NA, Wilkinson GA, Cooper GH, Wheeldon NM, Lynch J. Hemodynamic assessment of mitral mechanical prostheses under high flow conditions: comparison between dynamic exercise and dobutamine stress. J Heart Valve Dis 2006;15:87-91.

99. Tricoci P, Allen JM, Kramer JM, Califf RM, Smith SC Jr. Scientific evidence underlying the ACC/AHA clinical practice guidelines. JAMA 2009;301:831-41.

Key Words: exercise testing - valve - echocardiography - stress echocardiography. 